\title{
The implications of the cognitive sciences for the relation between religion and science education: the case of evolutionary theory
}

\author{
By Stefaan Blancke; Johan De Smedt, Helen De Cruz, Maarten Boudry and \\ Johan Braeckman
}

This paper has been accepted for publication in Science \& Education. The original
publication is available at $\underline{w w . S p r i n g e r l i n k . c o m ~}$

(http://www.springerlink.com/content/916q640348301511/)

\section{Introduction}

Evolutionary theory is notoriously difficult to properly understand. It involves emergent processes and complex systems (Chi 2005; Jacobson and Wilensky 2006); it introduces abstract prerequisite notions, such as population and undirected variation, and it depends both on blind forces and on a vast time frame (Dawkins 1986). Furthermore, the acceptance of evolutionary theory is hampered by emotional obstacles, such as an attachment to the existence of a caring and omnipotent creator, and to an immortal soul (Thagard and Findlay 2010). Also, learning and understanding evolutionary theory requires much more than merely absorbing new information. Previous work has highlighted specific cognitive obstacles to understanding evolutionary theory, such as essentialist thinking about species, the human penchant for teleological reasoning, and our ability for agency detection.

Students are more inclined to reject evolutionary theory when they are presented with alternatives deeply anchored in their intuitive theories, such as creationism and intelligent design. The global rise of creationist activity has therefore severe consequences for the position of evolutionary theory in science education (Blancke et al. in press). In this paper, we widen the scope of this discussion by exploring the implications of human biases not only for creationism, but for religion in general. In particular, we focus on the relation between evolutionary theory and religious views on the origin of life's diversity and complexity and the origin of humans. ${ }^{1}$ As we will see, religion in general, and not just creationist religion, appeals to precisely the cognitive intuitions that hinder an understanding of evolution. ${ }^{2}$

We begin by briefly challenging the popular view that science and religion are compatible, a view that suggests that learning and understanding evolutionary theory has no effect on students' religious beliefs and vice versa. We then proceed to develop a cognitive perspective on how students manage to reconcile evolutionary theory with their religious beliefs. Relying on the distinction and interaction between intuitive and reflective beliefs, we

\footnotetext{
${ }^{1}$ Because we will deal here with universal aspects of the human mind, we do not have a particular religion in mind. Nevertheless, the following discussion will be particularly relevant for, and is therefore primarily intended at, learning and understanding evolutionary theory in relation to Christian beliefs.

${ }^{2}$ The distinction between creationist and other Christian belief systems might appear somewhat artificial in the sense that any form of Christianity introduces the belief that God somehow created this world. We will use the word creationism here to indicate the belief that God has actively and directly intervened in this world, whether in the construction of the universe, in the creation of species or the design of biological functional complexity (adaptations). Such creationist beliefs often come with a resentment against evolution. Non-creationist religious beliefs hold that God created through secondary laws, that is, indirectly and thus tend to be more sciencefriendly.
} 
underwrite the claim developed by cognitive scientists and anthropologists that religion is natural because it taps into people's intuitive understanding of the natural world, which is constrained by essentialist, teleological and intentional biases. After having briefly contrasted the naturalness of religion with the unnaturalness of science, we discuss the difficulties cognitive and developmental scientists have identified with learning and accepting evolutionary theory in relation to the biases mentioned above. Next, we indicate how religious beliefs impede students' understanding and acceptance of evolutionary theory. We then discuss a number of options available to students for reconciling an informed understanding of evolutionary theory with their religious beliefs. To conclude, we discuss the implications of our account for science and biology teachers.

\section{Religion and biological education: are they compatible?}

Moderate and liberal religious leaders typically claim that evolutionary theory is compatible with their faith and make no attempt at opposing science education (see, for instance, the list of religious organizations in Sager 2008). The rationale behind this compatibilism is that science and religion cover separate domains of knowledge, a position defended by religious and non-religious authors alike. Famously, palaeontologist Stephen Jay Gould (1997) proposed that science and religion constitute non-overlapping magisteria (NOMA). Whereas science is interested in the natural world and how it operates, religion deals with the meaning of life and with moral issues. The most common compatibilist position today states that science is by definition committed to searching natural explanations for natural phenomena. For instance, Philosopher Robert Pennock (1999, p. 284) claims that "science does not have a special rule just to keep out divine interventions, but rather a rule that it does not handle any supernatural agents or powers since these are taken by definition to be above natural laws". The supernatural ${ }^{3}$ is absent from science, but that is not to say that the supernatural does not exist. Science simply lacks the methods to say anything meaningful about the supernatural, which is the exclusive proper domain of religion. As science is neutral with regard to different worldviews, one can practice science while still being a devout Christian or Muslim.

This view on science and religion, which has been termed methodological naturalism, is propounded by the (American) National Academy of Sciences and the National Center for Science Education, as well as by philosophers of science (e.g., Pennock 1999), religious and non-religious scientists (e.g., Miller 1999; Scott 2004), theologians (e.g. Haught 2000), and religious leaders (Sager 2008). Educational scientists too (e.g., Nelson et al. 1998; Sinatra and Nadelson 2011; but see Chinn and Buckland 2011for a differing opinion) support this view, stressing the importance of a correct understanding of science in science education; this position offers the additional advantage of reassuring students that evolutionary theory does not pose a threat to their religious convictions.

However, the identification of science with naturalistic explanations, and religion with supernatural explanations is less clear-cut than is often assumed. Historically, the view that science has no authority over supernatural causes was not the default position in scientific practice: in On the origin of species, for instance, Darwin (1859) repeatedly compared the explanatory merits of his theory of evolution by natural selection with what he referred to as the theory of special creation. Rather than discarding special creation for its appeal to

\footnotetext{
${ }^{3}$ Here, we will apply the term 'supernatural' as some of the authors have defined it elsewhere (Boudry et al. 2010), namely as "referring to any phenomenon which has its basis in entities and processes that transcend the spatiotemporal realm of impersonal matter and energy described by modern science."
} 
supernatural causes, Darwin took the program of natural theology quite seriously as a rival explanatory model. For instance, he writes:

$[\mathrm{N}]$ ature is prodigal in variety, but niggard in innovation. Why, on the theory of Creation, should this be so? Why should all the parts and organs of many independent beings, each supposed to have been separately created for its proper place in nature, be so invariably linked together by graduated steps? Why should not Nature have taken a leap from structure to structure? On the theory of natural selection, we can clearly understand why she should not; for natural selection, we can clearly understand why she should not; for natural selection can act only by taking advantage of slight successive variations; she can never take a leap, but must advance by the shortest and slowest steps. (Darwin 1859, p. 194)

In doing so, Darwin was not being unscientific; he was merely demonstrating that his new model - which happened to be naturalistic - was superior to the old one relying on supernatural origins. The outlook of modern science is naturalistic indeed, as Boudry and colleagues (2010) have argued, but this should not be construed as a definitional matter or self-imposed limitation on science. Rather, the naturalistic outlook is a contingent result of scientific progress over the centuries. Supernatural causes are amenable to scientific investigation, but our current understanding of the world simply shows no need for such explanations.

At an educational level, the compatibilist position suggests that learning evolutionary theory has no bearing on students' religious beliefs, and that, conversely, religion has no negative effect on students' learning of evolutionary theory. However, if the separation between science and religion is philosophically shaky, and both compete in the same explanatory realm, we are invited to take a closer look at the relation between religion and the learning of evolutionary theory from a cognitive perspective. Mahner and Bunge (1996) have argued that religion and science are incompatible because they are different at a doctrinal, metaphysical, methodological and attitudinal level and that this incompatibility extends towards religious and science education. Our cognitive account expands on their analysis, although we draw somewhat different conclusions.

\section{The naturalness of religion}

Central to our cognitive approach is the distinction and interaction between reflective and intuitive beliefs. Reflective beliefs are the kind of beliefs we are all familiar with, because we entertain them on a conscious level and use them in our explicit reasoning. Intuitive beliefs, by contrast, are automatically generated by the brain when presented with appropriate cues. The latter beliefs, though people are not aware that they have them, affect or constrain reflective beliefs in important ways. Sometimes they act as a default for reflective beliefs, in other cases they determine which reflective ideas seem more plausible (J. L. Barrett and Lanman 2008). The more reflective beliefs are in tune with intuitive beliefs, the more sense they make, or, in other words, the more natural they feel. As a result, such beliefs are easily represented, remembered and transmitted and become more widely dispersed.

This distinction between intuitive and reflective beliefs forms an essential component to our understanding of cultural evolutionary processes in general (Sperber 1996). Reflective beliefs that are anchored into intuitive beliefs have a better chance of becoming stable cultural representations. Because religious beliefs has been found to be prevalent among all cultures, 
cognitive scientists and anthropologists have come to apply this framework to the study of religion as well (Boyer 2001). Researchers in the cognitive science of religion claim that religion is natural (McCauley 2000) because it taps extensively into people's intuitive and non-reflective modes of reasoning, including essentialist, teleological and intentional intuitions.

\subsection{Essentialism}

Anthropological and historical research shows that humans naturally and spontaneously think along essentialist lines (Atran 1994; Mayr 1991). People mentally carve up nature into categories, the members of which share a similar inner essence. This essence or core defines their being, accounts for their properties and behaviour, and guides their development (Medin and Ortony 1989; Gelman 2004). The probable evolutionary function of psychological essentialism is that it allows for a wide range of inductive inferences (H. Clark Barrett 2001): for instance, people are able to predict the ontogenetic development of organisms, e.g., flowers turn into fruits and eggs into birds - both fruits and birds are good for eating. Threeyear-olds readily infer that inherited traits trump external circumstances: they correctly predict that an apple-seed, planted in a flower-pot, will grow into an apple tree and not into a flower (Gelman and Wellman 1991). Children also resist the idea that organisms can change category membership through superficial alterations (Keil 1989). Five-year-olds know that painting a raccoon to make it look like a skunk does not change it into a skunk. Nor would a surgical operation: an animal altered through surgery to resemble a member of another species is still a member of the original species. Four-year-olds think that a young goat, raised by kangaroo foster parents, will not hop but rather climb like goats do, even though it may never meet another goat in its life (Gelman and Wellman 1991). It is important to note that children's knowledge of essences does not result from enculturation by their parents. Indeed, children are stauncher essentialists than adults of the same culture. For example, Indian children (but not adults) believe that a Brahmin child will remain Brahmin, even when raised by untouchables; five-year-old British children believe that French babies brought up by English-speaking parents will grow up to speak French (for an overview, see Gelman et al. 1994; Gelman 2004).

\subsection{Teleology}

People intuitively assume that animals and plants have parts serving purposes that are beneficial for their owners, such as claws in cats for climbing or defence, or thorns in plants to prevent them from being eaten. This style of reasoning has been termed 'teleology' - it is an explanatory strategy that invites us to see the purpose or goal of a given structure as a necessary and sufficient explanation for its existence. Teleology allows children to learn useful facts about organisms. Even three-year-olds can infer the diet of an unfamiliar animal based on the shape of its beak, or predict that an unfamiliar mammal with webbed feet lives in the water (Kelemen et al. 2003). In western philosophy, teleology has become an explicit assumption at least since Aristotle, but preliminary cross-cultural studies indicate that it is also found in other cultures, such as the Shuar, Native Americans from the Andes. Like westerners, the Shuar classify animals and plants according to their functional parts, and think about these parts in terms of goal-directedness (H.Clark Barrett 2004). Children often provide or endorse teleological explanations even when these are inappropriate, a tendency that Kelemen (1999a, 1999b) termed 'promiscuous teleology'. Five-year-olds believe that lions exist 'to go in the zoo', and that clouds hang above us 'for raining' (Kelemen 1999a, 1999b; Kelemen et al. 2003). Until the age of about 10 children prefer teleological accounts to non- 
teleological mechanistic accounts. When asked whether rocks exist because 'bits of stuff piled up for a long period of time' or 'so that animals could scratch on them when they got itchy', children typically prefer the latter account - rocks are there for a reason (Kelemen 2003). Again, this knowledge does not simply derive from their parents, who actually prefer natural over teleological explanations in conversations with their children (Kelemen et al. 2005).

During adolescence, the preference for teleological explanations wanes: although we know that mountains can be climbed, we are not inclined to say that they exist for climbing in the first place. This is probably due to the acquisition of mechanistic, non-teleological explanations during education. In the case of mountains, we have learned about formation by plate-tectonic or volcanic activity. Similarly, when schooled, children by the age of ten no longer ascribe purposes to non-living natural objects, and they explain biological properties mainly in terms of self-serving rather than social or other-serving functions (Kelemen 1999b; Kelemen and Di Yanni 2005). In uneducated adults, however, the teleological tendency remains unscathed (Casler and Kelemen 2008). Moreover, even in the minds of educated adults teleological explanations are not completely eradicated. In one experiment, elderly people were given a choice between teleological and non-teleological explanations. In contrast to healthy seniors, Alzheimer's patients showed a re-emerging preference for teleological accounts (Lombrozo et al. 2007). For instance, they thought that it rains so that plants and animals have water to drink and grow, rather than choosing the acquired mechanical explanation that rain occurs by water vapour condensing into clouds and forming droplets. Similarly, in speeded judgment tasks, where schooled adults have to choose very quickly between teleological and non-teleological explanations, they too show an increased tendency to reason teleologically (Kelemen and Rosset 2009). It appears that the teleological tendency acts as a mental default setting for understanding the natural world, and that as such, it never really disappears.

\subsection{Agency detection, intentionality and the design stance}

The human mind is prone to detecting agents, even when only presented with the most basic cues. For instance, when confronted with contingent movements of dots on a computer screen or a suspicious sound, our mind automatically infers the presence of agents (Guthrie 1993). This tendency to over-detect agency makes good evolutionary sense. In ancestral environments, where predators and other humans formed a constant threat, detecting agents was often a matter of life and death. In such a situation, it is better to be safe than sorry. Mistaking the wind rustling through the leaves for an agent is far less costly than making the opposite mistake. Moreover, because we are social animals, being watched by human or human-like agents may have serious effects on one's reputation, whether beneficial or detrimental. Humans have been shown to behave more altruistically in response to minimal cues of being watched, like pictures of eyes inducing people to be more generous when having to leave money in a donation box in a canteen (Bateson et al. 2006). The crucial role of agents in human survival and sociality provides a plausible explanation of our ability to discriminate between (human) agents and inanimate objects and to reason differently about what causes their motion (Spelke et al. 1995). We also hold different expectations as to what specific actions the members of each category are capable of. For instance, 12-month-old infants expect the ultimate cause of a moving inanimate object to be an agent (Saxe et al. 2005). They also assume that agents, but not inanimate objects, are capable of creating order out of disorder (Newman et al. 2010). Most importantly, they interpret human agents' goaldirected behaviour in terms of intentions (Gergely et al. 1995). By the age of five, this intentional stance expresses itself in our reasoning about artefacts. Children spontaneously 
understand artefacts as having been construed with a particular purpose or function in mind; one study suggests that even 3-year-olds categorize artefacts not on the basis of their shape, but according to their intended function (Diesendruck et al. 2003). Dennett (1987, pp. 16-17) referred to this function-based attitude towards artefacts as "the design stance".

Humans adopt both the intentional and the design stance in accounting for the natural world as well. Creation stories worldwide explain the existence of the world in terms of intentional acts of superhuman agents (Leeming and Leeming 1995) and, in both religious and scientific contexts, complex functional features of organisms are commonly compared to human artefacts (De Cruz and De Smedt 2010; Recker 2010). Evans (2001) noted a preference for creationism in elementary school children, and Kelemen and DiYanni (2005) found a significant connection between children's teleological reasoning and their creationist assumptions. In their study with Alzheimer's patients, however, Lombrozo and colleagues (2007) found a dissociation between these two factors. Likewise, Samarapungavan and Wiers (1997) found a variety of responses when probing Dutch children's reasoning about origins: only $10 \%$ of these subjects endorsed explicitly creationist ideas. These findings suggest that belief in creationism probably does not result directly from ready-made creationist intuitions. However, because creationism taps into our intuitive expectations concerning intentional agents, people will readily endorse them when they are culturally available (Evans 2000a; Petrovich 1997). The prevalence of creationist stories about (the origin of) the natural world throughout human history and around the globe demonstrates their enduring intuitive appeal.

Studies probing into young children's concepts of God show that their understanding of God's mind is firmly anchored in intuitive psychology (Lane et al. 2010; Makris and Pnevmatikos 2007; Shtulman 2008). Conversely, available religious beliefs and representations involving anthropomorphised supernatural agents have a strong intuitive appeal. Moreover, these religious beliefs confirm the intuitive expectations people have. As such, it can be expected that the more intensely religious beliefs are adhered to, the stronger these beliefs will bolster or enforce those intuitions. Diesendruck and Haber (2009), for instance, have found that children of orthodox Jews resort more to essentialist and teleological thinking than children of secular Jews. These findings indeed suggest that there is a connection between religiosity and the effect of cognitive biases on individuals' representations of the natural world.

\section{The unnaturalness of science}

The intuitive appeal and naturalness of religion stands in sharp contrast to the unnaturalness of science (McCauley 2000). Scientific beliefs contradict many intuitive expectations about the world. These need to be overcome in order to understand science, a process that requires years of intense training. This holds for general relativity, electromagnetism, plate tectonics, and other highly counterintuitive theories, and even for concepts such as physical inertia or the spherical shape of our planet (Vosniadou et al. 2008). In the same vein, evolutionary theory is not readily assimilated by a mind that is intuitively inclined to discern essences, purposes and intentions in the natural world. The theory holds that species do not reflect immutable essences, but rather represent populations of individual organisms whose characteristics are distributed around a mean average changing with every new generation. The apparent purposes that can be discerned in nature are merely the result of a slow, gradual process by which organisms become adapted to their environment. Evolutionary innovation is not intentional, but rather arises from the retention of undirected variations. 
Essentialist, teleological and intentional intuitions have nurtured recurrent and predominant themes in Western thought about the natural world. Essentialism was a central element in Platonic and Aristotelian thinking, which dominated biological thought until well into the 19th century (De Cruz and De Smedt in press). Darwin himself witnessed the effects of our cognitive biases when his contemporaries tended to misconstrue evolution by natural selection as a directed and intentional process. The question of whether talk of teleology is legitimate in biology (i.e., whether the functions of traits like the eye can be explained in terms of purposes) continues to be a bone of contention in philosophy of biology, with prominent thinkers on both sides of the debate. For example, Ayala (1970) and Ruse (2003) argue in favour of teleology as a result of blind design: although selective processes are not goal-directed, the structures arising from them are. Papineau (2005), on the other hand, contends that teleology should be excised from biological discourse: the function of a trait is not a result of its purpose, but a consequence of the fitness advantages it bestowed on ancestral organisms. We realize that these debates are more substantive but we do not intend to engage with this discussion here. Yet, discussions like these underscore that, more than 150 years after Darwin laid the theoretical foundations for our modern understanding of the biological world, it remains unclear whether or not teleological reasoning constitutes a crucial component of our understanding of evolution.

\section{5. (Mis)understanding evolutionary theory}

A series of studies on the understanding of evolutionary theory confirms this picture of science's unnaturalness. Shtulman and Shultz (2008) found that people who think along essentialist lines are more likely to misunderstand evolutionary theory. The study by Samarapungavan and Wiers (1997) mentioned above, which probed beliefs on the origin of species until late childhood, found that children entertain various models, including essentialism, creationism and even Lamarckism, but not a single child was able to restate the principles of evolutionary theory. The closest were the so-called 'dinosaur-essentialists', who believe that each species alive today has a dinosaur-ancestor: cats descended from dinosaurcats, giraffes from dinosaur-giraffes, etc. Evans (2000b) too found that children who prefer evolutionary explanations believed evolution to be working in a Lamarckian fashion, by with changes occur directly to meet the needs of organisms. Even in high school, students keep encountering difficulties with the concept of natural selection, often thinking that organisms 'have to' develop a given trait in order to survive. In these accounts (see e.g., Bardapurkar 2008 for a collection), adolescents regard the function of a trait as a sufficient causal explanation of its existence, which accords with teleological reasoning but not with evolutionary theory. A sixteen-year-old girl claimed that arctic foxes developed a thick fur because they were so cold. A high school student thought that ducks needed to evolve webbed feet in order to move around more swiftly in the water. Adolescents also assume that organisms can pass on acquired traits to the next generation. Even youngsters with some knowledge of genetics keep falling back on Lamarckian explanations: for example, they believe that children of two white parents living in Africa will be born with a darker skin, because their chromosomes would already have adapted to the tropical climate.

A cause for concern is that not only children and students but biology teachers too are susceptible to misunderstanding evolutionary theory (Rutledge and Mitchell 2002). In a review article of surveys on misconceptions about natural selection, Gregory (2009, p. 163) concludes: 
Three decades of research have produced unambiguous data revealing a strikingly high prevalence of misconceptions about natural selection among members of the public and in students at all levels, from elementary school pupils to university science majors. [...] It is particularly disconcerting and undoubtedly exacerbating that confusions about natural selection are common even among those responsible for teaching it.

And he notes that "[m]ost of these [misconceptions] derive from deeply held conceptual biases that may have been present since childhood" (Gregory 2009, p. 172). These biases are so persistent that even scientists cannot always resist their influence (De Cruz and De Smedt 2007).

Learning evolutionary theory does not simply entail adding new information to the stock of knowledge, but requires thorough conceptual change. Students need to lift the concepts by which they reason about a particular domain of the natural world out of their intuitive - that is, essentialist, teleological and intentional - frameworks and bring these concepts to use in a scientifically informed understanding of that domain (Carey and Spelke 1994; Vosniadou et al. 2008). Such conceptual change involves not simply enriching but actually restructuring students' knowledge, a goal that can only be achieved by employing educational tools and strategies specifically designed for that purpose.

One crucial step towards a correct understanding of evolutionary theory is to make students aware of their own misconceptions (Vosniadou and Ioannides 1998; González Galli and Meinardi 2011). By letting students explain biological phenomena in their own terms, their implicit beliefs are brought to the fore, allowing teachers to identify any errors and misconceptions. Teachers can also confront students with biased representations of evolutionary theory in computer games (Bean et al. 2010) or science fiction stories (González Galli and Meinardi 2011), in order to assist them in examining their own conceptions. Students will be more prone to change their minds when teachers present them with concrete experiences and real-life examples (Vosniadou and Ioannides 1998; Sinatra et al. 2008). Applying evolutionary theory to cases with which students are already familiar, such as genetically modified food (Sinatra et al. 2008), or cases that intrigue them, like forensics (Evans 2008), will motivate them to find the study of the theory more appealing.

Teachers should also be careful about what language they use when talking about evolution. Adaptations, for instance, are often explained in teleological or intentional terms. When we are confronted with a complex and functional biological feature, the question arises what it is for, suggesting that it has evolved with the goal of performing a particular function. Animals are said to adapt to their environment as if they need or want to do so. When rightly interpreted, such language need not be problematic. Evolutionary scientists often speak in such terms as shorthand for more complex processes and phenomena. Indeed, need-based reasoning might provide the necessary scaffolding for students to learn to appreciate the concept of selective pressure, which forms an essential step towards the comprehension of natural selection (Evans and Lane 2011). However, when teachers neglect to point out the metaphorical nature of teleological language, they might not override but actually entrench students' biased understanding of the theory ${ }^{4}$.

\section{Religion and the understanding and acceptance of evolutionary theory}

\footnotetext{
${ }^{4}$ (Evans 2008; Evans et al. 2011; González Galli and Meinardi 2011; Sinatra et al. 2008)
} 
Learning and accepting evolutionary theory becomes even more difficult when students are supplied with models that tap into and hence enforce their incorrect intuitions. Creationism is only one of these models. In this paper, we argue that more liberal religious positions tend to have the same effect. Although they are claimed to be compatible with evolution, the way they envisage evolutionary processes often appeals to people's intuitive understanding as well. For instance, in 1996 the late Pope John Paul II declared that evolutionary theory is "more than a hypothesis", indicating that said theory could be reconciled with Roman Catholic faith. In the same text, however, he distinguished between several theories of evolution (materialist, reductionist and spiritualist) and noted "with man, then, we find ourselves in the presence of an ontological difference, an ontological leap, one could say" (John Paul II 1996). These qualifications illustrate that he did not accept the entire scientific corpus of evolutionary theory, especially not the evolutionary study of the human mind. The pope believed that the human "spiritual soul", unlike the human body, had been "immediately created by God" at some point during hominid evolution. This ontological leap endowed humans with divine essences while their bodies were prepared by evolution. We form the ultimate goal of a purposeful evolutionary process intended by God. In other words, although John Paul II paid lip service to evolutionary theory, he actually endorsed a version of evolution that was infused with religious beliefs tied to Catholic dogma. The Pope represented evolution as a teleological and intentional process which prepares bodies for receiving particular essences such as the human soul. Moreover, the representation is also constrained by an intuitive human/non-human distinction (De Cruz and De Smedt 2007) and an intuitive dualism that regards mind and body as part of separate ontological realms (Bloom 2004). Both ideas are unsupported by modern biology and neurology.

We do not intend to say that Pope John Paul II did not understand evolutionary theory, but rather that his religious convictions prevented him from accepting evolution by purely natural processes, and, concomitantly, led him to embrace a version of evolution anchored in essentialist, teleological and intentional intuitions. When young people are raised in a cultural environment in which religious authorities endorse such views on evolution, one might expect that their understanding of evolutionary theory would be adversely affected. Even when students are able to attain a full-fledged understanding of the theory, such views retain not only their intuitive but also their emotional and social appeal. As such, they might still prevent students from accepting evolutionary theory.

For religious students who have learnt and come to accept evolutionary theory, such an amalgam of religious and scientific views on the natural world might not suffice and lead to cognitive dissonance. The model outlined by the previous Pope raises several difficult questions. Why would a perfectly natural evolutionary process suddenly be interrupted by divine intervention? Did God simply wait for a suitable hominid lineage to emerge, or did he steer evolution in a particular direction? But then what to make of the undirected character of evolution according to modern science? And how did God manage to infuse biological organisms with immaterial souls? If students want to maintain their religious faith, they need better ways of reconciling it with evolutionary theory. To be sure, recent theological accounts (e.g., Haught 2000) have attempted to respect scientific findings and to reconcile a theistic worldview with the randomness, lack of direction, and animal and human suffering that results from evolution. The question whether such theistic evolutionary accounts are philosophically successful has elicited considerable debate in philosophy and theology that goes beyond the scope of this paper. In the next sections, we will examine whether such a reconciliation is possible at a cognitive level. 
Preston and Epley (2009) found that people experience what they call "an automatic opposition" between explanations in terms of God and scientific explanations. A poor scientific explanation for the origin of life and the universe led subjects to favour explanations involving God. Conversely, when a compelling religious explanation was offered, this had a significant negative effect on participants' evaluation of scientific explanations. Preston and Epley (2009, p. 240) conclude: "These data suggest that using scientific theories as ultimate explanation can serve as an automatic threat to religious beliefs, and vice versa." In an attempt to account for this phenomenon, however, Preston and Epley (2009, p. 240) only considered two possibilities: either the results "stem from an automatic causal discounting", which means that an argument for one type of cause counts against other causes, and vice versa. This is the option preferred by Preston and Epley. Another possibility is that the results "reflect an awareness of the opposition publicized in the popular culture." However, neither of these explanations is truly satisfactory, because they beg the question as to why people automatically causally discount either science or religion, or why science and religion are often diametrically opposed in popular culture.

The cognitive predispositions we discussed above provide a more plausible explanation. Religious beliefs make an appeal to our intuitions, whereas science typically flies in the face of those very same intuitions. On a cognitive level, religion and science are thus counteracting forces, pulling in opposite directions. Because they compete for the same explananda, religious and scientific explanations are engaged in a cognitive zero-sum game: if one accepts one type of explanation, one is less likely to find the other type plausible. As a result, religious beliefs enjoy a cognitive advantage over scientific theories, since the former explicitly formulate what people already intuitively endorse (J. L. Barrett 2010). Although scientific beliefs have a poor agreement with our intuitions, they too often enjoy widespread endorsement, for instance in the media (where the empirical successes of scientific practice are discussed) or in educational contexts (where science is viewed as the best model to understand the natural world). So why do people endorse science in spite of its lack of intuitive attractiveness? As Recanati (1997) has argued, deference to authorities and trust in testimony can lead people to hold beliefs they do not properly understand. For example, many westerners endorse that $\mathrm{E}=\mathrm{mc}^{2}$, even though most would be hard pressed to explain massenergy equivalence. This tension between endorsement on intuitive grounds and endorsement on testimonial grounds may lie at the basis of the popular opposition between science and religion. However, students who do know their science and accept it need to arrive at a religious understanding that is able to transcend this opposition of science and religion.

\section{Compatibilism revisited}

If, indeed, religious beliefs impede students' understanding and acceptance of evolutionary theory, one might conclude that students need to discard their religious beliefs first in order to arrive at a scientifically informed acceptance of evolutionary theory. Only in the absence of intuitively appealing alternatives, students will be able to override the intuitions that hinder their understanding of purely natural processes. However, religious beliefs are often of great significance, not only to the students personally, but also to the community they live in. Therefore, students will not feel inclined to sacrifice those cherished beliefs for the single purpose of attaining a more correct understanding of the natural world. Hence, we can expect their religious beliefs to be very persistent.

Religious people have tried out several ways to reconcile their faith with an informed understanding of evolutionary theory. The religious faith of founding figures of the modern 
synthesis, such as Theodosius Dobzhansky and Ronald Fisher, and other expert evolutionary biologists, such as Kenneth Miller and Francisco Ayala, illustrates that such a reconciliation is at least psychologically feasible. Next, we will discuss and evaluate some of the options religious students have taken in order to dissolve the cognitive opposition or tension they experience when they try to integrate a scientifically sound understanding of evolutionary theory with their faith.

One way to relieve this tension consists of putting religious and scientific explanations into a causal chain (Evans et al. 2011). In this view, at the beginning of the universe, God instigated natural laws through which his creative process unfolds. The processes that take place in the universe are therefore perfectly explicable in terms of secondary (i.e., natural) causes. By taking this position, which is known as theistic evolution, people's intuitive biases are redirected towards a domain of reality on which evolutionary theory is silent. As such, the position indeed allows students to reconcile evolutionary theory with their religious beliefs. However, students who expand their scientific knowledge into domains they had reserved for God, such as Big Bang cosmology, might learn that here too natural processes provide sufficient explanations. In other words, belief in a God who created everything with a Big Bang might be reconcilable with evolutionary theory, but it might not sit so well with scientific knowledge in other research domains, such as cosmology. For students who are interested in reconciling their religious beliefs with a scientifically informed view on the world, and not just one aspect of it, such a solution might appear entirely ad hoc.

A second option is for students simply to rely on different, even seemingly contradictory explanatory models when trying to make sense of the world, depending on the circumstances they find themselves in. Infants already use different causal inferences when making sense of the behaviour of agents compared to the motions of inanimate objects (Kuhlmeier et al. 2004). This causal flexibility supports the construction of multiple epistemologies that can be switched on and off depending on the domain (humans, animals, inanimate objects, etc.) people are dealing with (Evans et al. 2011). For our purpose, this would mean that a student switches to an evolutionary explanatory model when in the biology class and to a more intuitive model when confronted with religious views in religious education. Hence, by selectively using different kinds of epistemologies, cognitive conflict is avoided. However, not all students will feel comfortable with this solution. Although each of the epistemologies may be internally coherent, they may not always be mutually compatible. This is not to say that people always notice such inconsistencies (Benassi et al. 1980), nor that they always have the mental resources to resolve them. Indeed, provided that the cognitive distance between different beliefs is sufficiently large, inconsistencies go largely unnoticed and do not call for belief revision. However, Preston and Epley (2009) found that people experience an "automatic opposition" between religious and scientific explanations, which suggests that many students do experience cognitive conflicts between religious and scientific beliefs.

Although these models strive for a psychological integration of religious faith and belief in evolution by natural selection, they may not be satisfactory for all students: the first option reconciles faith and science at the expense of putting them into different time frames, and the second by putting them into different contexts. Students may circumvent these problems by taking a third option, adopting religious beliefs that involve abstract and highly counterintuitive representations of the supernatural (Lawson 2005). Such beliefs include the idea that God is not a being, but some sort of "ground of all being", and other beliefs that do not tap into students' folk psychology nor other intuitions that would otherwise conflict with 
their understanding of evolutionary theory. Such a level of theological sophistication may be difficult to achieve and maintain, however, and it may be unclear to students what exactly such religious conceptions boil down to. Barrett and Keil (1996) found that people who subscribe to complex and highly counterintuitive theological theses (e.g., God is ubiquitous) are still caught reasoning about God in everyday situations as if he were a physically and psychologically constrained agent, albeit one with superhuman powers. For instance, while they proclaim to believe in divine omniscience, they implicitly believe that God can only attend to one event at the time. Even after experimenters confronted their participants with the theological concepts they had explicitly subscribed to, people still continued to anthropomorphize God in most cases. This "theological incorrectness" (Slone 2004) entails that it will take a lot of pain and effort for students to fully embrace such abstract theological concepts. In fact, abandoning belief in God as a superhuman agent will require serious conceptual change. Before this difficult change is completed, however, it is very likely that even highly counterintuitive God talk will continue to trigger students' intuitive theory of mind. Even if they understand such highly counterintuitive God concepts, there is a substantial risk that students will simply refuse to accept them, because they conflict too much with their constrained notions of God.

If religious educators were to become aware of the intuitive appeal of many religious representations and of the cognitive constraints that need to be overcome in order to properly understand evolutionary theory, they could help their students considerably. It would be even more helpful if they themselves would actively propagate the kind of highly counterintuitive religious beliefs that do not contravene scientific knowledge. Within some denominations, this is already the case. However, we cannot expect religious educators to be much concerned with the quality of their pupils' knowledge and acceptance of evolutionary theory.

Much depends on which kind of religion children and adolescents are exposed to. Some denominations put less emphasis on the content of religious beliefs and focus more on religious practices (e.g., the history of particular parts of the liturgy, emphasizing mediation or prayer). Religions having most problems reconciling religious belief with science, such as evangelical forms of Christianity and most forms of Islam, typically hold what Dennett and LaScola (2010) have termed 'belief in belief'. As they put it "[m] ost people [in these religious communties] believe in belief in God; they believe that it is a state one should aspire to, work strenuously to maintain, and foster in others - and feel guilty or dismayed if one fails to achieve it" (Dennett and LaScola 2010, p. 125). Given the centrality of this belief in belief for religious believers, the cognitive tension between conflicting scientific and religious beliefs can become very strong, and tilt the psychological balance in favor of religion. By contrast, religions that place more emphasis on practice, such as Judaism, Roman Catholicism or Buddhism, have a higher acceptance of evolutionary theory.

There exists of course a fourth solution, by which students entirely give up their religious beliefs in favour of an exclusively naturalistic worldview. However, given the persistence of religious beliefs and the fact that they are often endorsed by the community students live in, this rarely happens. Nonetheless, the modes of reconciliation we discussed above show that a move towards agnosticism or atheism is not a necessary condition for students to understand and accept evolutionary theory. If students' religious beliefs are sufficiently malleable to adapt to newly acquired scientific information, this opens important perspectives for science teachers.

\section{Implications for science education}


We can expect that pupils will not modify their beliefs if teachers bluntly confront them with the incompatibility between their faith and evolutionary theory. If they feel that science infringes on religious beliefs that are important to them and their community, students will not feel motivated to study, let alone, accept evolution. A better strategy might be to gradually expose students to experiences and theoretical issues involving evolutionary biology, inducing them to reconsider and revise their religious beliefs. As students learn to appreciate natural selection as a sufficient explanation of biological 'design', they might no longer feel the need to represent God as an intentional agent who has constructed (aspects of) the natural world.

Studies indicate that this can be done from an early age onwards. Although five year old children anthropomorphise God significantly more than their parents do (Shtulman 2008), they are by that age also able to discriminate between natural and supernatural minds (Knight et al. 2004; Lane et al. 2010; Makris and Pnevmatikos 2007). In a false belief test, five-yearolds know that a normal person will think there are crackers in a box, when the child has been shown that the box actually contains rocks. However, the child assumes that God knows there are rocks inside, despite the misleading package. These findings show that by the age of five children's reasoning about natural and supernatural minds, albeit both anchored in their intuitive psychology, takes different developmental paths. This suggests that, from that age on, children's concepts of God have the potential of being gradually modified into more science-friendly representations, independent of their intuitive psychology.

It is definitely not the task of science teachers to introduce students to particular God concepts (indeed, in the USA this would violate the constitutional separation between church and state). However, science teachers happen to be in a position in which they provide students with experiences and theoretical issues that could induce them to revise their anthropomorphic God concepts. Recent studies suggest that biological education too can start from an early age: even five year old children are able to learn crucial aspects of evolutionary theory such as natural selection (unpublished study, cited in Kelemen in press). Evans and colleagues (2011, p. 150) describe how "[u]nderstanding the full import of evolutionary theory is a slow process, requiring a series of steps in which the counterintuitive nature of an evolutionary explanation is initially minimized". They propose that the first steps towards such an understanding can be taken from the age of five onwards. It is therefore recommendable that, even in elementary school, pupils are not exclusively exposed to anthropomorphised religious beliefs. Many young children today are exposed to such representations from an early age, in the form of animation movies, jigsaw puzzles and toys featuring the Garden of Eden or Noah's ark, and children's bibles. Most children are simply not familiar with the alternative, scientific explanations, since evolutionary theory is not taught at the level of elementary (primary) school. Hence the call of some educational psychologists (e.g., Fail 2008) to incorporate evolutionary theory already at this level. Indeed, a study with Italian children in elementary school has demonstrated that introducing them to evolution has a significant effect on their conceptions concerning the origin of species (Berti et al. 2010).

\section{Conclusions}

Taking a cognitive perspective on the difficult relation between religion and science education will not resolve all the issues involved. However, the above analysis suggests that cognitive modes of reconciliation are available that allow an informed understanding of evolutionary theory that is not in conflict with one's faith. In particular, by revising their anthropomorphic God concepts into more abstract notions, students will be able to switch off the intuitive 
modes of reasoning that hinder their understanding of evolutionary theory. This opens interesting perspectives for biology teachers who are confronted with religious students who are reluctant to accept evolutionary theory. They can teach the subject without necessarily posing a threat to the religious beliefs of their students. It goes without saying that science and biology teachers cannot impose a particular religious view on their students. However, they can gradually provide them with experiences and theoretical issues that might motivate them to adapt their beliefs to the newly acquired information. The earlier they do this, the better.

\section{Acknowledgments}

Parts of this paper have been presented at the annual meeting of the Society for the Scientific Study of Religion, October 27-30, 2010, Baltimore, Maryland. This research was supported by grants BOF08/24J/041 and COM07/PWM/001 from Ghent University and by the Fund for Scientific Research Flanders (FWO). We would like to thank the anonymous reviewers for their helpful remarks.

\section{References}

Atran, S. (1994). Core domains versus scientific theories: Evidence from systematics and itzamaya folkbiology. In L. Hirschfeld, \& S. A. Gelman (Eds.), Mapping the mind. Domain specificity in cognition and culture (pp. 316-340). Cambridge: Cambridge University Press.

Ayala, F. J. (1970). Teleological explanations in evolutionary biology. Philosophy of Science, $37(1), 1-15$.

Bardapurkar, A. (2008). Do students see the "Selection" In organic evolution? A critical review of the causal structure of student explanations. Evolution. Education and outreach, 1, 299-305.

Barrett, H. C. (2001). On the functional orgins of essentialism. Mind \& Society, 2(1), 1-30, doi:10.1007/bf02512073.

Barrett, H. C. (2004). Design versus descent in Shuar children's reasoning about animals. Journal of Cognition and Culture, 4(1), 25-50.

Barrett, J. L. (2010). The relative unnaturalness of atheism: On why Geertz and Markusson are both right and wrong. Religion, 40(3), 169-172, doi:10.1016/j.religion.2009.11.002.

Barrett, J. L., \& Keil, F. C. (1996). Conceptualizing a nonnatural entity: Anthropomorphism in god concepts. Cognitive Psychology, 31(3), 219-247.

Barrett, J. L., \& Lanman, J. A. (2008). The science of religious beliefs. Religion, 38(2), 109124, doi:10.1016/j.religion.2008.01.007.

Bateson, M., Nettle, D., \& Roberts, G. (2006). Cues of being watched enhance cooperation in a real-world setting. Biology Letters, 2(3), 412-414, doi:10.1098/rsbl.2006.0509.

Bean, T. E., Sinatra, G. M., \& Schrader, P. G. (2010). Spore: Spawning evolutionary misconceptions? Journal of Science Education and Technology, 19(5), 409-414, doi:10.1007/s10956-010-9211-1.

Benassi, V. A., Singer, B., \& Reynolds, C. B. (1980). Occult belief - seeing is believing. Journal for the Scientific Study of Religion, 19(4), 337-349.

Berti, A. E., Toneatti, L., \& Rosati, V. (2010). Children's conceptions about the origin of species: A study of Italian children's conceptions with and without instruction. Journal of the Learning Sciences, 19(4), 506-538, doi:10.1080/10508406.2010.508027. 
Blancke, S., Boudry, M., Braeckman, J., Smedt, J. D., \& Cruz, H. D. (in press). Dealing with creationist challenges. What European biology teachers might expect in the classroom. Journal of Biological Education, doi:10.1080/00219266.2010.546677.

Bloom, P. (2004). Descartes' baby. How child development explains what makes us human. London: Arrow Books.

Boudry, M., Blancke, S., \& Braeckman, J. (2010). How not to attack intelligent design creationism: Philosophical misconceptions about methodological naturalism. Foundations of Science, 15(3), 227-244, doi:10.1007/s10699-010-9178-7.

Boyer, P. (2001). Religion explained. The evolutionary origins of religious thought. New York: Basic books.

Carey, S., \& Spelke, E. (1994). Domain-specific knowledge and conceptual change. In L. Hirschfeld, \& S. A. Gelman (Eds.), Mapping the mind. Domain specificity in cognition and culture. Cambridge: Cambridge University Press.

Casler, K., \& Kelemen, D. (2008). Developmental continuity in teleo-functional explanation: Reasoning about nature among romanian romani adults. Journal of Cognition and Development, 9(3), 340-362, doi:10.1080/15248370802248556.

Chi, M. T. H. (2005). Commonsense conceptions of emergent processes: Why some misconceptions are robust. Journal of the Learning Sciences, 14(2), 161-199, doi:10.1207/s15327809jls1402_1.

Chinn, C. A., \& Buckland, L. A. (2011). Differences in epistemic practices among scientists, young earth creationists, intelligent design creationists, and the scientist-creationists of darwin's era. In R. S. Taylor, \& M. Ferrari (Eds.), Epistemology and science education. Understanding the evolution vs. Intelligent design controversy (pp. 38-76). New York: Routledge.

Darwin, C. (1859). On the origin of species by means of natural selection. Or the preservation of favoured races in the struggle for life. London: John Murray.

Dawkins, R. (1986). The blind watchmaker. Harlow: Longman Scientific \& Technical.

De Cruz, H., \& De Smedt, J. (2007). The role of intuitive ontologies in scientific understanding - the case of human evolution. Biology and Philosophy, 22(3), 351-368.

De Cruz, H., \& De Smedt, J. (2010). Paley's ipod. The cognitive basis of the design argument within natural theology. Zygon. Journal of Religion and Science, 45(3), 665-684, doi:10.1111/j.1467-9744.2010.01120.x.

De Cruz, H., \& De Smedt, J. (in press). Evolved cognitive biases and the epistemic status of scientific beliefs. Philosophical Studies.Dennett, D. C. (1987). The intentional stance. Cambridge: MIT Press.

Dennett, D. C., \& LaScola, L. (2010). Preachers who are not believers. Evolutionary Psychology, 8(1), 122-150.

Diesendruck, G., \& Haber, L. (2009). God's categories: The effect of religiosity on children's teleological and essentialist beliefs about categories. Cognition, 110(1), 100-114, doi:10.1016/j.cognition.2008.11.001.

Diesendruck, G., Markson, L., \& Bloom, P. (2003). Children's reliance on creator's intent in extending names for artifacts. Psychological Science, 14(2), 164-168.

Evans, E. M. (2000a). Beyond scopes. Why creationism is here to stay. In K. Rosengren, C. Johnson, \& P. Harris (Eds.), Imagining the impossible: Magical, scientific and religious thinking in children (pp. 305-331). Cambridge: Cambridge University Press.

Evans, E. M. (2000b). The emergence of beliefs about the origins of species in school-age children. Merrill-Palmer Quarterly-Journal of Developmental Psychology, 46(2), 221254. 
Evans, E. M. (2001). Cognitive and contextual factors in the emergence of diverse belief systems: Creation versus evolution. Cognitive Psychology, 42(3), 217-266, doi:10.1006/cogp.2001.0749.

Evans, E. M. (2008). Conceptual change and evolutionary biology: A developmental analysis. In S. Vosniadou (Ed.), International handbook of research of conceptual change (pp. 263-294). New York: Routledge.

Evans, E. M., \& Lane, J. D. (2011). Contradictory or complementary? Creationist and evolutionist explanations of the origin(s) of species. Human Development, 54(3), 144159, doi:10.1159/000329130.

Evans, E. M., Legare, C. H., \& Rosengren, K. S. (2011). Engaging multiple epistemologies. Implications for science education. In R. S. Taylor, \& M. Ferrari (Eds.), Epistemology and science education. New York: Routledge.

Fail, J. (2008). A no-holds-barred evolution curriculum for elementary and junior high school students. Evolution: Education and outreach, 1(1), 56-64, doi:10.1007/s12052-0070018-3.

Gelman, S. A. (2004). Psychological essentialism in children. Trends in Cognitive Sciences, 8(9), 404-409, doi:10.1016/j.tics.2004.07.001.

Gelman, S. A., Coley, J. D., \& Gottfried, G. M. (1994). Essentialist beliefs in children: The acquisition of concepts and theories. In L. A. Hirschfeld, \& S. A. Gelman (Eds.), Mapping the mind. Domain specificity in cognition and culture (pp. 341-365). Cambridge: Cambridge University Press.

Gelman, S. A., \& Wellman, H. M. (1991). Insides and essences. Early understandings of the non-obvious. Cognition, 38(3), 213-244.

Gergely, G., Knadasdy, Z., Csibra, G., \& Biro, S. (1995). Taking the intentional stance at 12 months of age. Cognition, 56(2), 165-193.

González Galli, L., \& Meinardi, E. (2011). The role of teleological thinking in learning the Darwinian model of evolution. Evolution: Education and outreach, 4(1), 145-152, doi:10.1007/s 12052-010-0272-7.

Gould, S. J. (1997). Nonoverlapping magisteria. Natural History, 106(2), 16-22.

Gregory, T. R. (2009). Understanding natural selection: Essential concepts and common misconceptions. Evolution: Education and outreach, 2(2), 156-175.

Guthrie, S. (1993). Faces in the clouds. A new theory of religion. New York: Oxford University Press.

Haught, J. F. (2000). God after Darwin : A theology of evolution. Boulder (Colo.): Westview press.

Jacobson, M. J., \& Wilensky, U. (2006). Complex systems in education: Scientific and educational importance and implications for the learning sciences. Journal of the Learning Sciences, 15(1), 11-34, doi:10.1207/s15327809jls1501_4.

John Paul II (1996). Truth cannot contradict truth. Address of Pope John Paul II to the Pontifical Academy of Sciences (october 22, 1996).

Keil, F. C. (1989). Concepts, kinds and cognitive development. Cambridge: MIT Press.

Kelemen, D. (1999a). The scope of teleological thinking in preschool children. Cognition, 70(3), 241-272.

Kelemen, D. (1999b). Why are rocks pointy? Children's preference for teleological explanations of the natural world. Developmental Psychology, 35(6), 1440-1452.

Kelemen, D. (2003). British and american children's preferences for teleo-functional explanations of the natural world. Cognition, 88(2), 201-221, doi:10.1016/s00100277(03)00024-6. 
Kelemen, D. (in press). Teleological minds. How natural intuitions about agency and purpose influence learning about evolution. In K. S. Rosengren, \& E. M. Evans (Eds.), Evolution challenges: Integtrating research and practice in teaching and learning about evolutionary theory. Oxford: Oxford University Press.

Kelemen, D., Callanan, M. A., Casler, K., \& Perez-Granados, D. R. (2005). Why things happen: Teleological explanation in parent-child conversations. Developmental Psychology, 41(1), 251-264, doi:10.1037/0012-1649.41.1.251.

Kelemen, D., \& Di Yanni, C. (2005). Intuitions about origins: Purpose and intelligent design in children's reasoning about nature. Journal of Cognition and Development, 6(1), 331.

Kelemen, D., \& Rosset, E. (2009). The human function compunction: Teleological explanation in adults. Cognition, 111(1), 138-143, doi:10.1016/j.cognition.2009.01.001.

Kelemen, D., Widdowson, D., Posner, T., Brown, A. L., \& Casler, K. (2003). Teleofunctional constraints on preschool children's reasoning about living things. Developmental Science, 6(3), 329-345.

Knight, N., Sousa, P., Barrett, J. L., \& Atran, S. (2004). Children's attributions of beliefs to humans and god: Cross-cultural evidence. Cognitive Science, 28(1), 117-126, doi:10.1016/j.cogsci.2003.09.002.

Kuhlmeier, V. A., Bloom, P., \& Wynn, K. (2004). Do 5-month-old infants see humans as material objects? Cognition, 94(1), 95-103, doi:10.1016/j.cognition.2004.02.007.

Lane, J. D., Wellman, H. M., \& Evans, E. M. (2010). Children's understanding of ordinary and extraordinary minds. Child Development, 81(5), 1475-1489.

Lawson, E. T. (2005). A new look at the science-and-religion dialogue. Zygon. Journal of Religion and Science, 40(3), 555-563.

Leeming, D. A., \& Leeming, M. A. (1995). A dictionary of creation myths. New York: Oxford University Press.

Lombrozo, T., Kelemen, D., \& Zaitchik, D. (2007). Inferring design - evidence of a preference for teleological explanations in patients with alzheimer's disease. Psychological Science, 18(11), 999-1006.

Mahner, M., \& Bunge, M. (1996). Is religious education compatible with science education? Science \& Education, 5(2), 101-123, doi:10.1007/bf00428612.

Makris, N., \& Pnevmatikos, D. (2007). Children's understanding of human and super-natural mind. Cognitive Development, 22(3), 365-375, doi:10.1016/j.cogdev.2006.12.003.

Mayr, E. (1991). One long argument. Charles Darwin and the genesis of modern evolutionary thought. London: Lane.

McCauley, R. N. (2000). The naturalness of religion and the unnaturalness of science. In F. C. Keil, \& R. A. Wilson (Eds.), Explanation and cognition (pp. 61-86). Cambridge: MIT Press.

Medin, D. L., \& Ortony, A. (1989). Psychological essentialism. In S. Vosniadou, \& A. Ortony (Eds.), Similarity and analogical reasoning (pp. 179-195). Cambridge: Cambridge University Press.

Miller, K. R. (1999). Finding Darwin's god. A scientist's search for common ground between god and evolution. New York: HarperCollins.

Nelson, C. E., Nickels, M. K., \& Beard, J. (1998). The nature of science as foundation for teaching science: Evolution as a case study. In W. F. McComas (Ed.), The nature of science in science education. Rationales and strategies (pp. 315-328). Dordrecht: Kluwer Academic Publishers. 
Newman, G. E., Keil, F. C., Kuhlmeier, V. A., \& Wynn, K. (2010). Early understandings of the link between agents and order. Proceedings of the National Academy of Sciences of the United States of America, 107(40), 17140-17145, doi:10.1073/pnas.0914056107.

Papineau, D. (2005). Philosophical problems of biology. In T. Honderich (Ed.), The Oxford companion to philosophy (pp. 97). Oxford: Oxford University Press.

Pennock, R. T. (1999). Tower of babel. The evidence against the new creationism. Cambridge: MIT Press.

Petrovich, O. (1997). Understanding of non-natural causality in children and adults: A case against artificialism. Psyche en Geloof, 8, 151-165.

Preston, J., \& Epley, N. (2009). Science and god: An automatic opposition between ultimate explanations. Journal of Experimental Social Psychology, 45(1), 238-241.

Recanati, F. (1997). Can we believe what we do not understand? Mind \& Language, 12(1), 84-100.

Recker, D. (2010). How to confuse organisms with mousetraps: Machine metaphors and intelligent design. Zygon. Journal of Religion and Science, 45(3), 647-664, doi:10.1111/j.1467-9744.2010.01119.x.

Ruse, M. (2003). Darwin and design. Does evolution have a purpose? Cambridge: Harvard University Press.

Rutledge, M. L., \& Mitchell, M. A. (2002). High school biology teachers' knowledge structure, acceptance, and teaching of evolution. American Biology Teacher, 64(1), 21-28.

Sager, C. (Ed.). (2008). Voices for evolution. Berkeley: The National Center for Science Education.

Samarapungavan, A., \& Wiers, R. W. (1997). Children's thoughts on the origin of species: A study of explanatory coherence. Cognitive Science, 21(2), 147-177.

Saxe, R., Tenenbaum, J. B., \& Carey, S. (2005). Secret agents: Inferences about hidden causes by 10-and 12-month-old infants. Psychological Science, 16(12), 995-1001.

Scott, E. C. (2004). Evolution vs. Creationism : An introduction. Berkeley (Calif.): University of California press.

Shtulman, A. (2008). Variation in the anthropomorphization of supernatural beings and its implications for cognitive theories of religion. Journal of Experimental PsychologyLearning Memory and Cognition, 34(5), 1123-1138, doi:10.1037/02787393.34.5.1123.

Shtulman, A., \& Schulz, L. (2008). The relation between essentialist beliefs and evolutionary reasoning. Cognitive Science, 32(6), 1049-1062, doi:10.1080/03640210801897864.

Sinatra, G. M., Brem, S., \& Evans, E. (2008). Changing minds? Implications of conceptual change for teaching and learning about biological evolution. Evolution: Education and outreach, 1(2), 189-195, doi:10.1007/s12052-008-0037-8.

Sinatra, G. M., \& Nadelson, L. (2011). Science and religion. Ontologically different epistemologies? In R. S. Taylor, \& M. Ferrari (Eds.), Epistemology and science education. Understanding the evolution vs. Intelligent design controversy (pp. 173193). New York: Routledge.

Slone, J. (2004). Theological incorrectness. Why religious people believe what they shouldn't. Oxford: Oxford University Press.

Spelke, E., Phillips, A., \& Woodward, A. L. (1995). Infants' knowledge of object motion and human action. In D. Sperber, D. Premack, \& A. J. Premack (Eds.), Causal cognition. A multidisciplinary debate (pp. 44-78). Oxford: Clarendon Press.

Sperber, D. (1996). Explaining culture. A naturalistic approach. Oxford: Blackwell. 
Thagard, P., \& Findlay, S. (2010). Getting to Darwin: Obstacles to accepting evolution by natural selection. Science \& Education, 19(6), 625-636, doi:10.1007/s11191-0099204-8.

Vosniadou, S., \& Ioannides, C. (1998). From conceptual development to science education: A psychological point of view. International Journal of Science Education, 20(10), 1213-1230.

Vosniadou, S., Vamvakoussi, X., \& Skopeliti, I. (2008). The framework theory approach to the problem of conceptual change. In S. Vosniadou (Ed.), International handbook of research on conceptual change (pp. 3-34). New York: Routledge. 